\title{
Estimation of Adenosine Deaminase Levels in CSF in Different Etiology of Meningitis
}

\author{
Anshul Bhateja', Gurpreet Singh ${ }^{2}$, Akritit ${ }^{3}$, Manpreet Kaur ${ }^{4}$ \\ ${ }^{1}$ Junior Resident, Department of Medicine, Government Medical College, Amritsar, ${ }^{2}$ Medical Officer Specialist, CHC, Fategarh Churian, Amritsar, ${ }^{3}$ Department of \\ Pathology, Christian Medical College, Ludhiana, ${ }^{4}$ Medical officer, PHC, Othian.
}

\section{Abstract}

Background: Meningitis is the most common sequelae to microbial invasion of the CNS and is more common in the developing countries than developed countries. Its Neurological sequalae are serious and rather common among survivors. Aim: To assess the difference in ADA activity in CSF in different types of meningitis and to differentiate between various etiologies of meningitis including pyogenic, tuberculous and viral meningitis using ADA levels in CSF. Subjects and Methods: The study included fifty patients $(\mathrm{n}=50)$ of meningitis, admitted in emergency, indoor medical wards and ICU of Guru Nanak Dev Hospital, Amritsar. The CSF specimens were obtained by lumbar puncture using all the aseptic precautions. CSF ADA was recorded by Giusti and Galantimethod. Results: Mean ADA levels in TBM was $19.09 \pm 8.16$ IU/l, In pyogenic meningitis was3.9- 6.39 $\pm 1.26 \mathrm{IU} / 1$ while in viral meningitis was $6.57 \pm 1.30 \mathrm{IU} / \mathrm{l}$. On comparison, CSF ADA was found to be markedly raised in TB meningitis, while lower ADA values are seen in PM and VM. Conclusion: It can be concluded that ADA estimation in CSF is inexpensive and rapid anda reliable method for diagnosis of tuberculousetiology in TBM as CSF ADA levels are is markedly raised in tubercular meningitis, while lower ADA values are seen in pyogenic meningitis and viral meningitis.

Keywords: Adenosine deaminase; Tuberculous meningitis; viral meningitis; pyogenic meningitis.

Corresponding Author: Dr. Gurpreet Singh, Medical Officer Specialist, CHC, Fategarh Churian, Amritsar.

Received: December 2019

Accepted: January 2020

\section{Introduction}

The central nervous system (CNS) may appear protected from the external environment by a blood brain barrier - a system of tight junction around capillaries that resist the entry of pathogens, inflammatory cells and macromolecules into the subarachnoid space and the brain. However, the barrier fails to resist the invasion of the microbes and its presence also causes difficulty in the delivery of antimicrobial agents in adequate concentration.

Meningitis is the most common sequelae to microbial invasion of the CNS and is more common in the developing countries than developed countries. Its Neurological sequalae are serious and rather common among survivors. ${ }^{[1]}$ Acute bacterial meningitis, viral meningitis, encephalitis, focal infections such as brain abscess, subdural empyema and infectious thrombophlebitis are distinct clinical presentations. ${ }^{[2]}$ The early diagnosis and treatment remains a challenge to the clinician. The classic triad of diagnostic signs consists of nuchal rigidity, sudden high fever, and altered mental status; however, all the three features are present in only $44-46 \%$ of bacterial meningitis cases. ${ }^{[3,4]}$

In tuberculous meningitis, the early manifestations are usually low-grade fever, malaise, headache (more than 50 percent of cases), slow mentation, confusion, and neck rigidity (75 percent of cases), with Kernig and Brudzinski signs. The seeding of tuberculous bacilli into CSF leads to development of clinical picture comprising of gradually fluctuating fever, weight loss, headache, behaviour changes and vomiting. Interventional delay leads to neurological deficits, loss of consciousness, seizures and it is the most common point of time when the diagnosis of tubercular meningitis is considered. Signs of cranial nerve involvement (usually ocular palsies, less often facial palsies or deafness) and papilledema may be present in TB Meningitis.

Viral meningoencephalitis, and particularly herpes simplex virus (HSV) encephalitis, can mimic the clinical presentation of bacterial meningitis. The typical CSF profile with viral CNS infections is a lymphocytic pleocytosis with a normal glucose concentration, in contrast to neutrophilicpleocytosis and hypoglycorrhachia, which is characteristic of bacterial meningitis. ${ }^{[2]}$

Partially treated patients with the use of inappropriate antibiotics can obscure the cytological and biochemical status of the spinal fluid and the chance of recovery of organisms from the spinal fluid will also become less. They can also simulate the CSF picture of viral meningoencephalitis.

In Enteroviral meningitis, the polymorphs can flood the CSF in first 6 hours along with normal CSF glucose. In immunosuppressed patients, the mounting of CSF 
inflammatory response is suboptimal and can also simulate the viral picture. Hence a quick and reliable method for differentiating bacterial and viral meningitis is essential for optimal management outcome.

Adenosine deaminase (ADA) is an enzyme in the purine salvage pathway that catalyzes the conversion of adenosine and deoxyadenosine to inosine and deoxyinosine respectively with the release of ammonia. It plays important role in differentiating lymphoid cells and is present in abundance in active T-lymphocytes whose concentration is inversely proportional to the degree of differentiation. ${ }^{[5]}$

Its levels are ten times higher in T-lymphocytes than in erythrocytes. The enzyme activity increases during mitogenic and antigenic responses of lymphocytes and $\mathrm{T}$ lymphocyte blastogenesis can be inhibited by inhibitors of ADA. ADA is now being recognized as a marker of cell mediated immunity particularly as a marker of $\mathrm{T}$ lymphocyte activation. Adenosine deaminase levels (ADA) have also been considered by several researchers to differentiate tubercular disease from non-tubercular. ${ }^{[6-10]}$

Therefore the present study was undertaken to assess the difference in ADA activity in CSF in different types of meningitis and to differentiate between various etiologies of meningitis including pyogenic, tuberculous and viral meningitis using ADA levels in CSF.

\section{Subjects and Methods}

This cross-sectional study was conducted in the Department of Medicine, Guru Nanak Dev medical college and Hospital, Amritsar. The study included fifty patients $(n=50)$ of meningitis, on the basis of clinical findings, CSF findings and MRI brain who were admitted to the emergency and ICU of the hospital.All those Patients who were diagnosed with meningitis and meningo-encephalitis were included in the study. While Patients of meningitis less than 14 years of age, with CVA/ stroke, with cirrhotic encephalopathy, those with uremic encephalopathy, with hypoxic ischemic encephalopathy and toxic-metabolic encephalopathy were excluded from our study.Information regarding their age, sex and clinical diagnosis was collected. Biochemical testing was performed in the department of Biochemistry of Govt. Medical College, Amritsar.This study was undertaken after approval of the Institutional Ethics Committee, Government Medical College, Amritsar. A Written informed consent of the patients was obtained in vernacular language for their inclusion.

All patients had undergone complete clinical examination of blood pressure, pulse rate and systemic examination, including detailed neurological examination. Meningitis patients were screened for the various biochemical and radiological parameters like CBC,CSF complete examination,CSF culture,Serum Electrolytes,Serum creatinine,Blood urea,Liver function tests and CSF adenosine deaminase levels.

Collection of CSF sample:

The CSF specimens were obtained by lumbar puncture using all the aseptic precautions; The following procedures were routinely performed on all CSF specimens: Protein, Glucose (Glucose Analyser), Analysis for total and differential leucocyte count and Gram stain, and culture on blood agar and heated blood agar. Chest X-ray, and ultrasound abdomen were done, when indicated.

Complete clinical examination and proper detailed history of all the meningitis patients admitted in medical wards was recorded, at the time of admission. Finally, the clinical evaluation was observed and recorded. According to the above mentioned criteria patients were diagnosed as Tuberculous, Pyogenic and Viral Meningitis.

Estimation of ADA in CSF:

We used Giusti and Galanti ${ }^{11}$ method for detection of CSF ADA levels based on the principle that Adenosine deaminase hydrolyses adenosine to ammonia and inosine. The ammonia formed further reacts with a phenol and hypochlorite in an alkaline medium to form a blue indophenol complex with sodium nitroprusside acting as a catalyst. Intensity of the blue coloured indophenol complex formed is directly proportional to the amount of ADA present in the sample. Reference range of $>10 \mathrm{U} / \mathrm{L}$ was considered as positive.

STATISTICAL ANALYSIS:

The data was collected systematically and analysed statistically according to the standard statistical methods using One way analysis of variance (ANOVA) and $p$ value $<0.005$ was considered as significant.

\section{Results}

A total of 50 patients were included in the study. Mean age of subjects in our study came out to be $41.6 \pm 17.1$ years with majority of subjects $(32 \%)$ belonging to the age group of 31-40 years.Male predominance was observed comprising of $62 \%$ males and overall, Male : female ratio in the present study observed was $1.63: 1$. Maximum male population was seen in age range of 21-30 years while maximum female population was seen in 41-50 and 61-70 years of age.

Further, in the present studywe included 17cases of tubercular meningitis, 16 cases of pyogenic meningitis and 17 cases of viral meningitis.ADA levels were found to be elevated $(\mathrm{ADA} \geq 10 \mathrm{IU} / 1)$ in $100 \%$ cases in TBM, Whereas $100 \%$ cases of pyogenic meningitis (16/16 cases) and $100 \%$ cases of viral meningitis presented with ADA levels $\leq 10$ IU/l. (Table 1, figure 1).

Table 1: Number of Cases Showing Elevated ADA Levels in Different Types of Meningitis

\begin{tabular}{|c|c|c|c|c|c|c|}
\hline \multirow{2}{*}{$\begin{array}{l}\text { CSF Analysis } \\
\text { ADA Levels } \\
\text { (IU/L) }\end{array}$} & \multicolumn{2}{|c|}{$\begin{array}{l}\text { TBM } \\
(\mathbf{N}=17) \\
\end{array}$} & \multicolumn{2}{|c|}{$\begin{array}{l}\mathrm{PM} \\
(\mathrm{N}=16)\end{array}$} & \multicolumn{2}{|c|}{$\begin{array}{l}\mathrm{VM} \\
(\mathrm{N}=17)\end{array}$} \\
\hline & $\mathrm{n}$ & $\%$ & $\mathrm{n}$ & $\%$ & $\mathrm{n}$ & $\%$ \\
\hline$\geq 10 \mathrm{IU} / 1$ & 17 & $100 \%$ & 0 & 0 & 0 & 0 \\
\hline$\leq 10 \mathrm{IU} / 1$ & 0 & 0 & 16 & $100 \%$ & 17 & $100 \%$ \\
\hline
\end{tabular}




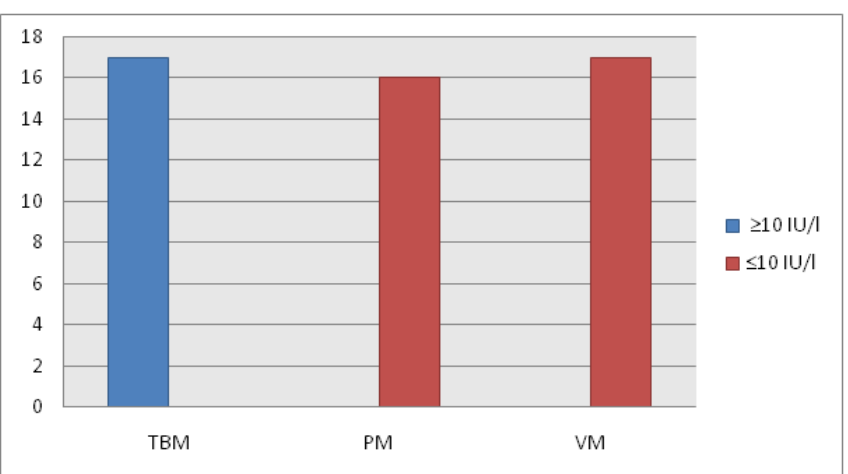

Figure 1: Number of Cases Showing Elevated ADA Levels in Different Types of Meningitis

ADA levels in different types of meningitis as observed showed that ADA levels in TBM were in the range of 11.135 IU/l with mean of $19.09 \pm 8.16 \mathrm{IU} / \mathrm{l}$, In pyogenic meningitis were 3.9-8 IU/1 with mean $6.39 \pm 1.26 \mathrm{IU} / 1$ while in viral meningitis were of 3.2-9 IU/l with mean of $6.57 \pm 1.30 \mathrm{IU} / \mathrm{l}$. On comparison, CSF ADA was found to be markedly raised in TB meningitis, while lower ADA values are seen in PM and VM. Hence, difference between ADA values between TBM \& PM and TBM \& VM in both the groups is statistically significant $(\mathrm{p}<0.0001,95 \% \mathrm{CI}=$ 60.6095 to 107.9505). (Table 2, graph 3).

Table 2: CSF ADA Levels and Diagnosis in Different Types of
Meningitis
\begin{tabular}{|l|l|c|c|l|}
\hline \multirow{2}{*}{ Diagnosis } & $\begin{array}{l}\text { Total No } \\
\text { of Patients }\end{array}$ & \multicolumn{2}{|c|}{$\begin{array}{c}\text { ADA Levels } \\
\text { (IU/L) }\end{array}$} & \multirow{2}{*}{ P Value } \\
\cline { 3 - 4 } & & $\begin{array}{c}\text { Min- } \\
\text { Max }\end{array}$ & Mean & \\
\hline TBM & 17 & $11.1-35$ & $19.09 \pm 8.16$ & \multirow{2}{*}{ P $<0.001^{*}$} \\
\hline PM & 16 & $3.9-8$ & $6.39 \pm 1.26$ & \\
\hline VM & 17 & $3.2-9$ & $6.57 \pm 1.30$ & \\
\hline
\end{tabular}

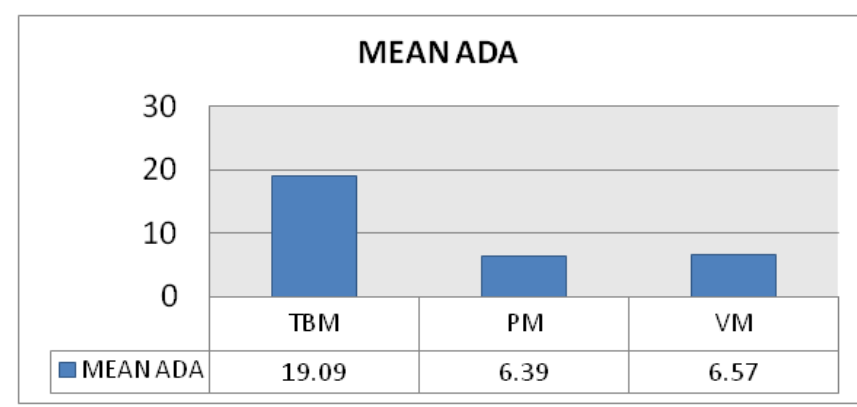

Figure 2: Mean CSF ADA Levels (IU/L) In Different Types of Meningitis in Present Study

\section{Discussion}

Estimation of CSF ADAhas been considered as a marker of cell-mediated immunity and its activity has been observed in various infections including TBM. Routine CSF laboratory findings may not be helpful to differentiate tuberculousetiology in meningitis from other causes. Considering that both humoral and cellmediated immunity play an important role in TBM infection, it has been suggested that ADA activity in CSF may help differentiate TBM from non-TBM infectious meningitis.

Therefore in the present study we aimed to differentiate different types of meningitis o basis of etiologiesincluding pyogenic, tuberculous and viral meningitis using ADA levels in CSF.

In the present study, ADA levels were found to be elevated $(\mathrm{ADA} \geq 10 \mathrm{IU} / \mathrm{l})$ in $100 \%$ cases in $\mathrm{TBM}$. Whereas $100 \%$ cases of both pyogenic meningitis $\mathrm{f}$ viral meningitis presented with ADA levels $\leq 10 \mathrm{IU} / 1$. ADA levels in TBM was in the range of 11.1-35 (IU/l) with mean of $19.09 \pm 8.16$ while in pyogenic meningitis, it was 3.9-8 (IU/l) with mean $6.39 \pm 1.26$ and in viral meningitis, it was 3.2-9 (IU/l) with mean of $6.57 \pm 1.30$.The results of our study showed that on comparison, CSF ADA is markedly raised in TB meningitis, while lower ADA values are seen in Pyogenic Meningitis and Viral Meningitis. On comparison, difference between ADA values between TBM \& Pyogenic Meningitis and TBM \& Viral Meningitis in both the groups is statistically significant.

In accordance to our results, previous studies done by Tuon FFet $\mathrm{al}^{[12]}$, Moghtaderi $\mathrm{A}$ et $\mathrm{al}^{[13]}$ Gupta et $\mathrm{al}^{[14]}$, Agarwal $\mathrm{S}^{[15]}$, Gautam et $\mathrm{al}^{[16]}$, Belagavi and Shalini ${ }^{[17]}$ and Mehta et $\mathrm{al}^{[18]}$ had shown that ADA levels were found to be significantly higher in TBM group as compared to bacterial and viral meningitis. On the contrary, Abdolbagi $\mathrm{MH}$ et $\mathrm{al}^{[19]}$ reported that the measurement of ADA level alone is not useful as a rapid diagnostic test for TBM.

Possible explanation for raised ADA levels can be because ADA has been considered as a marker of cellmediated immunity as it is released by $\mathrm{T}$ cells during cell mediated immune response (CMI) to the tubercle bacilli. Its activity has been observed in various infections including TBM. Considering that both humoral and cell-mediated immunity play an important role in TBM infection, it has been suggested that ADA activity in CSF may help differentiate TBM from nonTBM infectious meningitis.

Gupta et $\mathrm{al}^{14}$ observed that adenosine deaminase levels in nontuberculous disease rarely exceeded the cut-off; set for tuberculous disease. They have further observed that ADA estimation is not only a fairly sensitive and specific test (more than $90 \%$ ), helpful in differentiating tubercular from non-tubercular etiology; both in pulmonary and extra-pulmonary disease but is also simple, inexpensive and rapid. For this reason this test may help in early diagnosis, improve the prognosis and reduce spread of disease and sequlae. ${ }^{[20]}$

ChanderA et al ${ }^{[21]}$ reported that if the ADA assay result is negative, the probability that the patient has TBM is approximately $19 \%$, which is not low enough to rule out TBM. Thus they suggest, that a negative ADA assay result should not be used alone as a justification to exclude or discontinue anti-TB treatment. The choice of therapeutic strategy should be based on the 
results of microscopic examination of a smear or culture for Mycobacterium tuberculosis, as well as other clinical data, such as response to anti-TB treatment.

Similarly, Choi SH et al studied ADA activity in CSF of 182 patients with meningitis. The mean ADA level in tubercular group was 12.7 $\pm 7.5 \mathrm{U} / 1$ and it was significantly higher than the other groups. ${ }^{[22]}$ Chotmongkol $\mathrm{V}$ et al identified a CSF ADA level of $15.5 \mathrm{U} / 1$ as the best cut-off value to differentiate tubercular meningitis and non-tubercular meningitis, with sensitivity of $75 \%$ and specificity of $93.0 \%{ }^{[23]}$

\section{Conclusion}

CSF ADA is markedly raised in tubercular meningitis, while lower ADA values are seen in pyogenic meningitis and viral meningitis. Hence, we can suggest that estimation of these enzymatic activities can be helpful in diagnosing and differentiating pyogenic, tubercular and viral meningitis.

\section{References}

1. Greenwood B. Meningococcal meningitis in Africa. Transactions of the Royal Society of Tropical Medicine and Hygiene. 1999;93(4):341-53.

2. Roos KL, Tyler KL. Meningitis, Encephalitis, Brain abscess, and Empyema. In Harrison's Principles of Internal Medicine. 16th ed. NewYork: McGraw-Hill Professional; 2004. p.2471-90

3. Van de Beek D, De Gans J, Spanjaard L, Weisfelt M, Reitsma JB, Vermeulen M. Clinical features and prognostic factors in adults with bacterial meningitis. New Eng J Med. 2004;351(18):1849-59.

4. Attia J, Hatala R, Cook DJ, Wong JG. Does this adult patient have acute meningitis?.Jama. 1999;282(2):175-81.

5. Sharma SK, Mohan A. Adenosine deaminase in the diagnosis of tuberculosis pleural effusion. Indian $\mathrm{J}$ Chest Dis Allied Sci. 1996;38(2):69-71.

6. Malan C, Donald PR, Golden M, Taljaard JJ. Adenosine deaminase levels in cerebrospinal fluid in the diagnosis of tuberculous meningitis. J Trop Med Hyg. 1984;87(1):33-40

7. 14. Piras M.A., Gakis C.CFS..adenosinedeaminase activity in tuberculous meningitis. Enzyme. 1972-73;14:311-317

8. Kashyap RS, Kainthla RP, Mudaliar AV, Purohit HJ, Taori GM, Daginawala HF. Cerebrospinal fluid adenosine deaminase activity: a complimentary tool in the early diagnosis of tuberculous meningitis. Cerebrospinal Fluid Res. 2006;3:5.

9. Gupta B K, Bharat Vinay, BandyopadhyayDebapriya. Role of Adenosine deaminase estimation in differentiation of tuberculous and non-tuberculous exudative pleural effusions. J Clin Med Res. 2010 Apr;2(2):79-84.

10. Gupta B K, Bharat Vinay, BandyopadhyayDebapriya. Sensitivity, specificity, negative and positive predictive values of Adenosine deaminase in patients of Tubercular and Non-Tubercular Serosal Effusion in India. J Clin Med Res. 2010 Jun;2(3):121-126.

11. I Lutsar, S Haldre, M Topman, T Talvik. Enzymatic change in the cerebrospinal fluid in patients with infections of the central nervous system. ActaPaediatr. 1994;83:1146-50

12. Tuon FF, Higashino HR, Lopes I, Litvoc MN, Atomiya AN, Antonangelo L, et al. Adenosine deaminase and tuberculous meningitis-A systematic review with meta-analysis. Scand J Infect Dis. 2010;42:198-207.

13. Moghtaderi A, Niazi A, Alavi-Naini R, Yaghoobi S, Narouie B. Comparative analysis of cerebrospinal fluid adenosine deaminase in tuberculous and non-tuberculous meningitis. ClinNeurolNeurosurg. 2010;112:459-62.

14. Gupta BK, Bharat A, Debapriya B, Baruah H. Adenosine deaminase levels in CSF of tuberculous meningitis patients. J Clin Med Res. 2010;2(5):220-4

15. Agarwal S. Study of adenosine deaminase activity as a biochemical marker of cell mediated immunity in tuberculous meningitis, tuberculous pleural effusions and tuberculous ascites. J Medicine. 2012;13:32-38

16. Gautam N, Aryal M, Bhatta N, Bhattacharya SK, Baral N, Lamsal M. Comparative study of cerebrospinal fluid adenosine deaminase activity in patients with meningitis. Nepal Med Coll J. 2007;9(2):104-6.

17. Belagavi AC, Shalini M. Cerebrospinal fluid $\mathrm{C}$ reactive protein and adenosine deaminase in meningitis in adults. JAPI. 2011;59:557-60.

18. Mehta M, Shah J, Leuva AT. CSF ADA as diagnostic tool for tuberculous meningitis patients. NJIRM. 2012;3(3):160-4

19. Abdolbagi MH, Dezfuli AR, Soudbakhsh AR, Rasulinejad M, Golestani B. Diagnostic evaluation of adenosine deaminase in cerebrospinal fluid in tuberculous meningitis. Kanun Med J. 2006;8(4):23-8.

20. Giusti G. Adenosine deaminase. In: Bergmeyer H.U., editor. Method of enzymatic analysis. II. Florida: VCH Weinheim; 1974. p. 1072.

21. Chander A, Shrestha CD. Cerebrospinal fluid adenosine deaminase levels as a diagnostic marker in tuberculous meningitis in adult Nepalese patients. Asian Pac J Trop Dis. 2013;3(1):16-9.

22. Choi SH, KimYS, Bae IG, Chung JW, Lee MS, Kang JM, Ryu J, Woo JH. The possible role of cerebrospinal fluid adenosine deaminase activity in the diagnosis of tubercular.

23. Chotmongkol V, Teerajetgul GY, Yodwut C. Cerebrospinal fluid adenosine deaminase activity for the diagnosis of tubercular meningitis in adults. Southeast Asia J Trop Med Public Health. 2006;37:948-52

Copyright: (C) the author(s), 2019. It is an open-access article distributed under the terms of the Creative Commons Attribution License (CC BY 4.0), which permits authors to retain ownership of the copyright for their content, and allow anyone to download, reuse, reprint, modify, distribute and/or copy the content as long as the original authors and source are cited.

How to cite this article: Bhateja A, Singh G, Akriti, Kaur M. Estimation of Adenosine Deaminase Levels in CSF in Different Etiology of Meningitis. Asian J. Med. Res. 2019;8(4):ME44-ME47.

DOI: dx.doi.org/10.21276/ajmr.2019.8.4.ME7

Source of Support: Nil, Conflict of Interest: None declared. 